\title{
What is a True Gamer? The Male Gamer Stereotype and Marginalization of Women in Video Game Culture
}

\author{
Benjamin Paaßen* \\ CITEC Center of Excellence \\ Bielefeld University \\ Thekla Morgenroth \\ Department of Psychology \\ University of Exeter \\ Michelle Stratemeyer \\ Melbourne School of Psychological Sciences \\ University of Melbourne \\ 2016-09-11; Preprint Version \\ Final Version: DOI:10.1007/s11199-016-0678-y
}

\begin{abstract}
Women and men play video games in approximately equal numbers. Despite this similarity, video gaming is still strongly associated with men. A common justification for this stereotype is that, although women might play games, they should not be considered "true" or "hard-core" gamers because they play more casually and less skillfully compared to their male counterparts. In this contribution, we review the existing literature on gender and gaming to investigate the male gamer stereotype in terms of its accuracy, persistence, effects, and future perspective. We conclude that the stereotype varies in accuracy depending on the definition of "gamer." We further argue that the persistence of this stereotype can be explained by the fact that almost all professional and highly visible figures in gaming culture are male. On the other hand, female players who achieve a moderate level of competence are rendered invisible or are actively marginalized. We argue that the effects of the male gamer stereotype can be harmful to women, precluding them from the positive outcomes of video game play such as enhanced access to fields of science, technology, and engineering.
\end{abstract}

Keywords: Gender stereotypes; Gamer stereotypes; Video game culture; Video games; Female gamers

\footnotetext{
${ }^{*}$ Corresponding Author: bpaassen@techfak.uni-bielefeld.de
} 
Preprint of the publication Paaßen, Morgenroth, and Stratemeyer (2016). The final publication can be found at DOI:10.1007/s11199-016-0678-y

\section{Introduction}

Think of a "gamer"; who do you picture? According to Williams (2005, p.5), you might imagine "isolated, pale-skinned teenage boys [sitting] hunched forward on a sofa in some dark basement space, obsessively mashing buttons." Although recent research indicates that most people do not believe in the "isolated, pale-skinned" image anymore (Kowert, Festl, \& Quandth, 2014), the gamer image seems to remain strongly associated with being male (Shaw, 2010). The video game industry continues to create content that panders towards the presumed preferences of a young, male, heterosexual audience. These preferences are reflected in both a lack of female video game characters and hyper-sexualization of the female characters that do exist (Behm-Morawitz \& Mastro, 2009; Burgess, Stermer, \& Burgess, 2007; Dill \& Thill, 2007; Downs \& Smith, 2010; Martins, Williams, Harrison, \& Ratan, 2009; Ogletree \& Drake, 2007; Soukup, 2007; Williams, Martins, Consalvo, \& Ivory, 2009). The marginalization of women in gaming also receives widespread attention outside the scientific discourse; for example, Anita Sarkeesian's (Sarkeesian, 2013) video series titled "Tropes versus Women in Video Games" criticizes the stereotypical and negative roles of female characters in video games.

The response to such criticism has been extreme at times - a phenomenon Consalvo (2012) refers to as "toxic gamer culture." In particular, feminist video game critics have faced massive backlash in the course of the recent "\#GamerGate" debate. \#GamerGate originated as a campaign demanding ethics in video game journalism, but it became dominated by a vocal group of gamers who responded to feminist critiques with extreme online harassment including rape and death threats (Anita Sarkeesian has been one of the main targets in this regard Alexander, 2014; Chess \& Shaw, 2015, Wingfield, 2014). At the heart of this conflict is the alleged divide between a White, young, male community of hard-core gamers and the criticism of the gamer community by perceived feminist interlopers (Huntemann, 2013 Salter \& Blodgett, 2012). This notion of an almost exclusively male gaming community is articulated in several popular YouTube videos, such as those made by the users Summers (2014), Maddox (2013), The Amazing Atheist (2013), and thunderf00t (2014). These four users, who have had their videos viewed over 2.3 million times combined, argue that "video games are created by men for men" (Maddox, 2013, 0:17), and this is why developers pander to a male consumer base with strong male characters and sexy female characters.

However, the claim that women are only a small minority of gamers is contradicted by large-scale polls which have consistently shown that at least $40 \%$ of video game players are female (Entertainment Software Association, 2008, 2009, 2010, 2011, 2012, 2013, 2014, 2015; Interactive Software Federation of Europe, 2012). This apparent contradiction might be explained by stereotypes of how men and women play video games. Although women might play games, they are not considered true gamers. This is because women allegedly only play casually, playing "inferior games" (e.g., Candy Crush Saga or Farmville; please refer to Appendix A for more detail on the games mentioned in the present paper) on "inferior platforms" (such as smartphones Juul, 2009; Shaw \& Chess, 2016; Vanderhoef, 2013). 
Preprint of the publication Paaßen et al. (2016). The final publication can be found at DOI:10.1007/s11199-016-0678-y

As such, women supposedly exhibit less dedication and skill with respect to gaming. Conversely, men are thought to be "hard-core" gamers, playing more complex and competitive games on dedicated consoles, identifying with the gaming community, and sometimes even engaging in competitive electronic sports where they can earn prize money in international tournaments (T. L. Taylor, 2012).

In the present paper, we attempt to explain the deep-rooted association of video game play with the male gender by reviewing the existing literature on the topic. Three research questions guide our investigation. First, is it the case that gamers are predominantly men? To answer this question, we look at the existing research on gender differences in video game play. Second, what are the mechanics that perpetuate gendered gamer stereotypes? Here, we draw on the extensive research on stereotypes, in particular social role theory. Finally, what are the consequences of these stereotypes? For this question, we draw on the literature on the effects of games, the benefits of gamer status, and gendered effects of gaming. We also provide an outlook on the future of the male gamer stereotype and discuss interventions.

\section{Are Gamers Predominantly Male?}

First, we examine the accuracy of the gendered gamer stereotype. Jussim, Crawford, and Rubinstein (2015) suggest a three-step empirical process when assessing stereotype accuracy, namely (a) assessing people's descriptive beliefs about a group, (b) identifying criteria that establish group characteristics, and (c) comparing beliefs to criteria. In comparing beliefs to criteria, Jussim and colleagues suggest that a discrepancy of more than $20 \%$, or a correlation $r<.25$, indicates an inaccurate stereotype.

This standard seems to establish a rather simple assessment for our case. People believe that gamers are men (Kowert, Griffiths, \& Oldmeadow, 2012; Williams, Yee, \& Caplan, 2008). However, the polls of the Entertainment Software Association $(2008,2009,2010,2011,2012,2013,2014,2015)$, Interactive Software Federation of Europe (2012) show that more than $40 \%$ of gamers are female. The discrepancy between group beliefs and actual properties is larger than $20 \%$, thus the stereotype is inaccurate. This assessment, however, has two main problems. First, we do not know how large the male majority in the gaming community is believed to be. Second, and more importantly, it is not clear a priori which criteria establish characteristics of the gamer group. The figures provided by the Entertainment Software Association include anyone who engages in video gaming -independent of genre, platform, time-investment, or other features. Most likely, such a broad definition overestimates the group who are considered "true" gamers (Grooten \& Kowert, 2015; Poels, Annema, Verstraete, Zaman, \& De Grooff, 2012; Shaw, 2012). Depending on the definition of a gamer, stereotype accuracy might vary drastically.

A more systematic assessment of gamer stereotype accuracy is provided by two studies by Kowert et al. (2012, 2014). In the first study, the authors assessed beliefs about the stereotype of online gamers via a telephone survey and identi- 
Preprint of the publication Paaßen et al. (2016). The final publication can be found at DOI:10.1007/s11199-016-0678-y

fied a gamer stereotype using component analysis. They found that gamers were perceived as unpopular, unattractive, idle, and asocial, indicating a negatively valenced stereotype (Kowert et al., 2012). In the second study, they surveyed both gamers and non-gamers and compared their self-assessment with respect to the stereotyped attributes. No significant differences were found between gamers and non-gamers, suggesting that the stereotype is inaccurate (Kowert et al., 2014).

Still, this research does not settle the matter. First, the participants of the first study did not personally endorse the gamer stereotype, that is, they did not believe that gamers actually conform to the stereotypical description they provided (Kowert et al., 2012). Second, the studies did not consider gender as part of the gamer stereotype. Finally, in their second study, Kowert et al. (2014) defined gamers as anyone playing more than 1 min per day, which is still likely to overestimate the group of people seen as gamers.

In order to get a clearer picture of the accuracy of the male gamer stereotype, we need to consider more restrictive definitions of hard-core gamers. In academia, there are a plethora of such definitions (Grooten \& Kowert, 2015), which we will review briefly. We will then proceed to assess the accuracy of the gendered gamer stereotype with respect to each of these definitions.

Kowert and colleagues' (2014) approach of taking time-investment as the central criterion has been applied by other scholars as well (Poels et al., 2012; Royse, Lee, Undrahbuyan, Hopson, \& Consalvo, 2007; Williams, Consalvo, Caplan, \& Yee, 2009). However, the threshold to be considered a hard-core gamer varies, reaching from 1 min per day (Kowert et al., 2014) to $1 \mathrm{~h}$ per day (Poels et al., 2012). The latter study used time-investment only as an initial definition to find different parameters which correlate with hard-core versus casual gaming. Using qualitative interviews in small focus groups (of 4-7 participants), they found a lack of distinction between hard-core and casual gamers, with the exception of self-identification with the gamer label. Poels et al. (2012) report that, independent of gender, hard-core gamers were proud to be gamers, whereas casual gamers did not consider themselves as gamers. As such, hard-core gamers may be defined by their self-identification. Indeed, Shaw $(2012,2013)$ and Grooten and Kowert (2015) argue that the term "gamer" refers to a social identity rather than merely describing the act of playing video games (Grooten \& Kowert, 2015). In particular, the gamer identity is performed in out-of-game spaces, for example by taking part in game-related online fora, visiting video game conventions, or wearing gamingrelated clothing (Grooten \& Kowert, 2015, Shaw, 2012, 2013).

Other characteristics may also define the difference between casual and hardcore gamers. Ip and Jacobs (2005) used cluster analysis with survey data for video game market research. They identified two clusters, which they related to hardcore and casual gamers. The clusters were distinguished by three components: gaming knowledge and attitudes, playing habits, and buying habits. Vanderhoef (2013), as well as Vermeulen, Van Looy, De Grove, and Courtois (2011), distinguished hard-core and casual gamers by the genres of games they play - classifying shooters, massive multiplayer (role playing) games, and strategy games as hardcore game genres. Juul (2009) takes a similar route but lists design elements 
Preprint of the publication Paaßen et al. (2016). The final publication can be found at DOI:10.1007/s11199-016-0678-y

such as tolerance of interruptions and usability as distinguishing factors between hard-core and casual games.

Interestingly, none of the definitions mentioned includes video game skill as feature by which to identify hard-core gamers, even though assumed lower skill is an important part of the prejudice against casual gamers (Juul, 2009, pp. 3945; Salter \& Blodgett, 2012; Vanderhoef, 2013). This oversight might be due to difficulties in assessment. For instance, how would one compare the difficulty of a song in Guitar Hero to the difficulty of traversing a dungeon in World of Warcraft, or an opponent in Counter-Strike?

Because we have little a priori information supporting one or the other definition, we continue by assessing the actual gender distribution of gamers according to each of the criteria we discussed: time-investment, self-identification, genre, design elements and content, as well as skill. The one exception is Ip and Jacobs' (2005) survey-based definition of casual versus hardcore games because we did not find any other study applying it.

\section{$2.1 \quad$ Time-Investment}

Multiple studies have indeed found that women, on average, spend less time playing video games than men do (Hartmann \& Klimmt, 2006; Poels et al., 2012; Terlecki et al., 2011; Vermeulen et al., 2011). However, all of these findings are based on self-reported game time, which is subject to under-reporting effects that are particularly pronounced for women (Kahn, Ratan, \& Williams, 2014; Williams, Consalvo, et al., 2009). More specifically, Williams, Consalvo, et al. (2009) found that men in their sample underestimated their weekly play time by about $1 \mathrm{~h}$, whereas women underestimated their weekly play time by more than $3 \mathrm{~h}$. The authors attribute the under-reporting effect to issues of social desirability connected to problematic and compulsive play. Kahn et al. (2014) further connect under-reporting to cognitive dissonance theory and to balance theory, finding that players who fit less into the adolescent male gamer stereotype are more likely to under-report.

To our knowledge, only two studies have assessed play time more directly, namely the works by Williams, Consalvo, et al. (2009) and Ratan, Taylor, Hogan, Kennedy, and Williams (2015). In both cases, the authors assessed play time or number of game sessions using direct access to the game servers (Everquest 2 in the former case and League of Legends in the latter). Moreover, both studies feature impressive sample sizes $(N=7,129$ and $N=18,627$ respectively). In the former study, the authors found that female participants had a higher average play time than did male participants. This finding was especially pronounced for the top $10 \%$ of players in terms of time-investment, with women on average playing $8 \mathrm{~h}$ more per week than men did. In the latter study, the authors found that men played more game sessions than women did. However, the effect size was small $(d=.30)$, which is not sufficient to judge the stereotype as accurate according to Jussim, Cain, Crawford, Harber, and Cohen (2009), who require an effect size of $d \geq .8$ for an accurate stereotype. 
Preprint of the publication Paaßen et al. (2016). The final publication can be found at DOI:10.1007/s11199-016-0678-y

Additional context for gender differences in time-investment is provided by Winn and Heeter (2009). In a survey of 276 undergraduate students, women, on average, had less leisure time to spend on games than men did. This pattern suggests that women's reduced time-investment in gaming might not necessarily be a result of innate preference, but rather of practical necessity. Furthermore, we note that this time-investment stereotype is likely only accurate for players who play far more than the norm. This categorization includes, for example, e-sports athletes (i.e., avid video game players who compete in international tournaments). Taking part in such tournaments requires intense training of several hours a day (T. L. Taylor, 2012). Among e-sports athletes, there are almost no female players. For example, among the top 100 players in terms of earnings, none are female (esportsearnings.com, 2016).

Another example of extreme players are so-called speedrunners, who compete by playing through a single-player game as fast as possible, relying on intricate knowledge of the game mechanics or even specific bugs and glitches in the source code (Parker, 2008). Interestingly, this branch of video game culture seems not to have received much scholarly attention to date. To roughly estimate female participation, we looked at three recent, large speedrunning events (the 2015 Awesome Games Done Quick event and the 2014 as well as 2015 Summer Games Done Quick event). We assessed gender using video footage. (We acknowledge that such an assessment is problematic if applied to non-cisgender expressions. Further, we excluded two participants due to videos not being available.) Of the 153, 136, and 117 runners featured in the events, 3, 0, and 6 runners respectively were women (i.e., less than $2 \%$ on average).

A final example of players with high time-investment are people who suffer from gaming addiction or engage in problematic play. The most common self-report indicators of problematic play are playing more than planned, playing even though one does not really want to play, and playing excessively. All three are strongly connected to high time-investment. Because definitions of problematic play vary among studies, it is not surprising that researchers report different prevalence rates ranging from 1.3\% (Haagsma, Pieterse, \& Peters, 2012) to $11.9 \%$ (Grüsser, Thalemann, \& Griffiths, 2006).

With regards to gender, Mentzoni et al. (2011) found that problematic video game play is more likely among men and among adolescents with a prevalence of $15.4 \%$ in men between 16 and 21 years-old $(n \approx 82)$ and $2.5 \%$ for women in the same age group $(n \approx 127)$. However, the gender difference in problematic play prevalence is much smaller for older age groups. For both men and women, it is below $3 \%$ for the age groups $28-33$ years-old $(n \approx 200)$ and $34-40$ yearsold $(n \approx 242)$. We also note that the self-reporting scales used in the study might underestimate women's play time due to the same under-reporting effects mentioned previously. Overall, we observe that the male gamer stereotype is only moderately accurate when considering time-investment outside the extremes, but becomes more accurate if very strict criteria on time-investments are applied. 
Preprint of the publication Paaßen et al. (2016). The final publication can be found at DOI:10.1007/s11199-016-0678-y

\subsection{Self-Identification}

Quantitative accounts of gender differences in gamer self-identification are provided by two studies. As part of their study on gamer stereotypes, Kowert et al. (2012) found that, of 176 self-identified gamers studied, only $14.4 \%$ were female, whereas $85.6 \%$ were male. Further, in a survey of about 1400 U.S. teenagers, Burch and Wiseman (2015) found that only $35 \%$ of female adolescents identified as gamers, whereas fully $69 \%$ of young men did.

The discrepancy between women and men self-identifying as gamers might be explained by a conflict between the gamer identity and the gendered identity of women. Storla (2011), as well as T. L. Taylor (2012, pp. 122-125), connect the gamer identity to the "nerd" identity of being overly intellectual, obsessive, and socially awkward, which is typically associated with men rather than with women (Bucholtz, 2002; Fine, 2010, pp. 87-91). We note that the masculinity of men who engage in gaming might be challenged by their identities as nerds and outsiders as well (Burch \& Wiseman, 2014; Kowert et al., 2012; T. L. Taylor, 2012, pp. 111115). However, we agree with T. L. Taylor (2012, pp. 128-129) that the conflict between male identity and gamer identity has been alleviated in the last few years as teenagers increasingly play video games and playing popular games may even accrue social capital for young males (Burch \& Wiseman, 2014). Women, on the other hand, can only embrace either a gamer identity or a gender identity. This conflict is intensified by marketing practices of video game publishers which target a young, male consumer base (Shaw, 2012).

Royse et al. (2007), as well as Daviault and Schott (2013), further argue that female players who spend a lot of time gaming internalize a fluid understanding of gender, whereas women with less play time see gaming as strictly associated with males and so are less likely to identify themselves with gaming culture. This idea is consistent with findings in related areas. Prescott and Bogg $(\overline{2013})$ found that women in the games industry have internalized a more androgynous gender identity. Similarly, Bucholtz (2002) notes that women working in technology-based jobs identify more strongly with their profession than with their gender; and Fine (2010) discusses several studies which show that women in technological fields tend to identify less with their gender compared to women outside such fields. On the other hand, Ogletree and Drake (2007) found no significant difference in gender identification between women who play a lot and women who do not. Overall, we find some evidence of gender-differences in self-identification, which appear to be less pronounced for younger players.

\section{$2.3 \quad$ Genre}

Previous studies have identified specific hard-core game genres (shooters, massive multiplayer games, real-time strategy games), which may separate casual from hard-core gamers (e.g. Vanderhoef, 2013; Vermeulen et al., 2011). In an online survey distributed on a gaming website with 962 participants, Vermeulen et al. (2011) found that $85.9 \%$ of men in their sample played games in the hard-core genre, whereas only $42.7 \%$ of women did. This corresponds to $21.7 \%$ of hard- 
Preprint of the publication Paaßen et al. (2016). The final publication can be found at DOI:10.1007/s11199-016-0678-y

core players being female (the overall sample consisted of $64.2 \%$ men and $35.8 \%$ women). Similarly, Burch and Wiseman (2015) report that 16-26\% of female adolescents in their sample of around 1400 teenagers played games from genres which are considered hard-core. Harwell (2014) cites the research company newzoo for statistics on the gender distribution of players of popular video games (the number of participants is not provided). For shooter games (Halo, Call of Duty), 27 and $28 \%$ of players were female, whereas $29 \%$ of players of a strategy game (League of Legends) were female. For all other games listed, female participation was even higher. The lowest estimate is provided by Ratan et al. (2015) who found that only $4 \%$ of participants in their study on League of Legends were female $(N=18,627)$.

Taken together, with the exception of the last study, most data seem to indicate that between 16 and $29 \%$ of players of hard-core genre games are women, indicating some gender difference. With an upper-bound estimate of a third of players being female, we argue that the male gamer stereotype appears unsupported by evidence. However, we acknowledge that a lack of empirical data on expectations of gamer gender presents significant challenges in drawing such conclusions.

\subsection{Design Elements and Content}

A number of authors list design elements as critical to the definition of a gamer (e.g. Hartmann \& Klimmt, 2006; Juul, 2009, p. 50; Vermeulen et al., 2011). For instance, Juul (2009) defines five design elements to distinguish hard-core games from casual games. First, he suggests that hard-core games feature a negative fiction, that is, a dark and violent setting, such as a war zone, which can be related to violent video game content. Both Hartmann and Klimmt $(2006, N=317)$ and Vermeulen et al. (2011, $N=962$ ) report that women in their samples dislike ingame violence more than men do. Unsurprisingly, this difference was partially explained by genre preference, such that women and men who played core-genre games were less annoyed by in-game violence compared to others, and this effect was stronger for women than for men. These patterns suggest that male and female players of core genres are more similar than male and female game players overall. Further, Hartmann and Klimmt (2006) report no gender differences in preference for role playing games (RPGs), which are oftentimes quite violent. Consider, for example, the highly popular Dragon Age franchise, which has been rated "adult only" by PEGI (2016) due to "extreme violence".

Juul (2009) suggests three further features which define hard-core games in opposition to casual games: low usability, high difficulty, and a lack of "juiciness," which refers to strong visual rewards for players' achievements. All of these features relate to the challenges a game poses to a player. Vermeulen et al. (2011) report that female players preferred games with clear and manageable challenges. Casual games that feature such challenges, such as Candy Crush Saga and Farmville, are predominantly played by women (Haferkamp \& Herbers, 2012, Harwell, 2014; Juul, 2009). As in the case of violent game content, Vermeulen and colleagues (2011) report that the preference for complexity is explained by genre preference. 
Preprint of the publication Paaßen et al. (2016). The final publication can be found at DOI:10.1007/s11199-016-0678-y

The difference in complexity preference between women and men is smaller for players of hard-core game genres than for other players.

As a final feature by which to define hard-core games, (Juul, 2009, pp. 36-39) suggests "non-interruptibility". Hard-core games require players to spend time in a prolonged game session, which is not the case for casual games. Winn and Heeter (2009) report that women not only have less time to spend on games overall, but also less time per game session (less than $30 \mathrm{~min}$ on average, whereas men spend more than $1 \mathrm{~h}$ per session on average). As such, women might prefer casual games due to time constraints rather than because of innate preferences.

We also note that at least some of the findings with respect to gendered preference in game design are contradictory. For example, (Hartmann \& Klimmt, 2006) state that women prefer social interaction within games, whereas Vermeulen et al. (2011) report the opposite. Both studies find that hyper-sexualization might deter women from gaming, whereas Reinhard (2009) finds no such effect. Taken together, the research on game design and content seems to suggest that there is some accuracy in the stereotype of the male gamer but that the division between gamers is not as straightforward as presuming that women are casual gamers and men are hard-core gamers.

\subsection{Skill}

Few studies directly assess skill levels required for specific video games and genres. Brown, Hall, Holtzer, Brown, and Brown (1997) found that men outperformed women in Pong but that both genders showed significant performance increases in the course of the study. More recently, Ratan et al. (2015) surveyed over 18,000 League of Legends players. They utilized the skill measure devised by the game's developers and reported that men, on average, had a significantly higher skill level than did women. However, the effect size for their study $(d=.35)$ suggests a relatively small gender difference. Moreover, they found that women accrued skill at the same speed as men, indicating that the difference in skill was mainly driven by the fact that men had, on average, played more matches than did women (Ratan et al., 2015). In other words, if women spent the same time playing League of Legends, they would match male players on skill level.

We also note the effect of stereotype threat on female gamer's performance in playing video games. Stereotype threat has been introduced by Steele and Aronson (1995) as the negative effect that salient negative group stereotypes can have on group member's performance. For instance, women who are reminded of their gender identity before a cognitive ability test (e.g., a math test) tend to perform worse than women who receive no such reminder (for a meta-analytic review of this literature, see Nguyen \& Ryan, 2008). Both Vermeulen, Castellar, Janssen, Calvi, and Looy (2016) and Kaye and Pennington (2016) found that gaming performance for women could be negatively affected by evoking the "girls can't play" stereotype; as such, stereotype threat might play a role in reported performance differences between the genders. In conclusion we can suggest that, as with time-investment, the male gamer stereotype is only accurate if we restrict our sample to highly 
Preprint of the publication Paaßen et al. (2016). The final publication can be found at DOI:10.1007/s11199-016-0678-y

skilled players.

\subsection{Conclusion About Predominately Male Gamers}

Overall, our review of the literature indicates that the accuracy of the male gamer stereotype depends on the strictness of the stereotype as well as the strictness of the gamer definition. Generally, the less restrictive the stereotype is (i.e. the more women are believed to be gamers as in "some women are gamers" versus "no women are gamers"), the more accurate the stereotype becomes. Conversely, the narrower the definition of "gamer" and the fewer people included in this definition (e.g., hard-core gamers versus casual), the more accurate the stereotype becomes. However, if one allows some participation by women and considers gaming as a whole, then the stereotype of gaming as a men-only domain unravels. It therefore seems puzzling that a stereotype which is only accurate for a very small minority of niche gamers persists so stubbornly. In the next section, we explore the mechanics that perpetuate the stereotype in detail.

\section{The Mechanics Behind the Male Gamer Stereo- type}

Stereotypes of gamers differ depending on whether they are defined by gamers themselves or by observers of gamers. Kowert et al. (2012) found that selfidentified gamers were aware that the gamer stereotype described them as unpopular, unattractive, idle, and asocial, but they found the stereotype more inaccurate than did non-gamers. But how does stereotype content differ between in-group and out-group perspectives? The stereotype content model (Fiske, Cuddy, Glick, $\& \mathrm{Xu}, 2002$ ) suggests that stereotypes of any groups can be described using two dimensions: warmth and competence. The gamer stereotype description by Kowert et al. (2012) is negative on both axes, describing gamers as lacking both competence and warmth. However, self-descriptions of gamers often highlight competence and skill, as well as competitiveness, as important characteristics of gamers (Royse et al., 2007; Salter \& Blodgett, 2012; T. L. Taylor, 2012; Vanderhoef, 2013). Such a description is high on competence but low on warmth. Incidentally, this configuration matches that of stereotypical men (Fiske et al., 2002).

Thus, stereotype content informs our understanding of self-identification and self-stereotyping as a gamer. Self-stereotyping has been described by social identity theory (Tajfel, 1974) and self-categorization theory (Turner, Oakes, Haslam, \& McGarty, 1994). It refers to the description of one's self in relation to the stereotype of a group to which one belongs - for example, the extent to which a woman describes herself as caring and nurturing or an academic describes herself as intelligent but lacking social skills. The extent to which self-stereotyping occurs depends on many factors, such as the salience of one's group membership or the perceived overlap between the representation of the in-group and the self (Latrofa, Vaes, Cadinu, \& Carnaghi, 2010). 
Preprint of the publication Paaßen et al. (2016). The final publication can be found at DOI:10.1007/s11199-016-0678-y

These theories help to explain why males are more likely to identify as gamers compared to females. Men perceive a stronger overlap between their gendered identity and their gamer identity, facilitating social identification and self-stereotyping. For women, the opposite is likely to happen: because their gendered identity conflicts with the gamer identity (Storla, 2011; T. L. Taylor, 2012, pp. 122-125) they may be less likely to describe themselves in terms of the gamer-stereotype. Furthermore, self-stereotyping has been shown to increase if there is a perceived threat to the in-group's status (Spears, Doosje, \& Ellemers, 1997). This finding is consistent with the observations of Juul (2009), Huntemann (2012), Salter and Blodgett (2012), and Vanderhoef (2013), all of whom suggest that gamers feel their community is threatened by feminist critics and changes in the games market, such as the rise of so-called casual games. Status may also be involved in perpetuating the male gamer stereotype in a different way. Once gender differences in status-relevant parameters within the gaming community exist - for example because male players invest more time and as a result achieve a higher level of skill and performance-higher status is prescribed to males even if their playing behavior does not objectively differ from females (Ridgeway, 2013).

Another perspective on stereotypes is offered by social role theory (Eagly \& Steffen, 1984; Koenig \& Eagly, 2014). This theory suggests that the distribution of members of different groups into social roles shapes stereotype content. For example, women are over-represented in caregiving, communal professions, which results in them being viewed as nurturing and warm. Evidence for this theory exists with respect to a wide range of groups (e.g., Black men and women, gay men, the poor, and senior citizens) and social roles (e.g., secretaries, hair stylists, food service, and store clerks), and the authors explicitly suggest its applicability to leisure and recreational roles as well (Koenig \& Eagly, 2014).

In relation to video game culture, a gendered association with gaming might arise if more men than women are seen performing the social role of a gamer. Thus, it is informative to consider high visibility groups who perform the social role of a gamer. Media depictions of gamers often invoke images of young, White, male gamers who play excessively (Grooten \& Kowert, 2015; Williams, 2003). Indeed, it seems that the gamer stereotype in broader society is mostly driven by problematic play (Kowert et al., 2012, 2014). However, this image does not necessarily hold for the in-group. For gamers, a broader range of figures have high social role visibility. Consider, for example, e-sports athletes and speedrunners. These groups combine high competence and high status with high visibility. More importantly, almost all of them are men.

Other highly visible figures within video game culture are video game reviewers. Reviewing video games has become one of the most influential practices in video game culture, aside from playing games itself. We define "review" rather loosely, and include professional video game journalists, as well as amateur video game players who display their game play live via online streaming while commenting on it (so-called "let's plays"). Amateur "let's plays" videos draw huge audiences on established video portals such as YouTube and twitch.tv. Consider the example of PewDiePie, whose videos are viewed about 300 million times per month (Stark, 
Preprint of the publication Paaßen et al. (2016). The final publication can be found at DOI:10.1007/s11199-016-0678-y

2015), indicating high visibility. To our knowledge, there is no existing research on the gender distribution of video game reviewers. We therefore provide our own estimates of gender distribution in the field.

To account for professional reviewer estimates, we evaluated all video game review sites in the top 100 of Alexa's (2016) "Top Sites in Video Games" and assessed reviewer gender via staff listings provided by the sites (destructoid.com, eurogamer.net, gamasutra.com, gameinformer.com, gamesradar.com, giantbomb.com, ign.com, pcgamer.com, and rockpapershotgun.com). Alexa was chosen because it is a large and established source for large-scale analyses of this sort (Vaughan \& Yang, 2013). Two sites (gamespot.com and n4g.com) were excluded because no staff information was available. Further, we excluded five staff members of destructoid.com because we could not assess their gender. This resulted in a sample of 200 staff members; of these, 28 (14\%) were female and $172(86 \%)$ were male. Regarding "let's plays," we base our estimation on the 100 most subscribed gaming channels on YouTube, according to vidstatx.com (2015) "One hundred most subscribed games \& gaming channel rankings list by subscribers." In this case, only two channels featured female reviewers (one female host and one female cohost). In comparison, 84 channels had exclusively male hosts, with the remaining 14 channels belonging to groups or organizations.

The invisibility of women holds true in online game spaces as well. Lenhart, Smith, Anderson, Duggan, and Perrin $(2015)$ report that only $28 \%(n \approx 45)$ of female adolescents use voice chat in online games, whereas $71 \%(n \approx 285)$ of male adolescents do. As a result, female players who are performing the role of gamer are unlikely to be identified as female. Rather, other players are likely to default to the norm and presume they are male (Cote, 2015). Further, because women are often introduced to a game by male friends or romantic partners, they are often perceived as fulfilling not the role of a gamer, but of a romantic partner (Ratan et al., 2015; Williams, Consalvo, et al., 2009).

The same argument holds for the public performance of the gamer identity in forms of fandom (Grooten \& Kowert, 2015; Shaw, 2012, 2013). The most visible expression of fandom are gaming conventions such as E3 in the United States, the different PAX installments in the United States and Australia, or Gamescom in Germany. Although statistics on the demographics of convention visitors are unavailable to us, we have qualitative accounts such as those provided by Huntemann (2012), who mentions an overwhelming male majority at such conventions. Other arenas for fandom are on-site e-sports tournaments and large scale LAN parties (events where players connect their computers in a local area network, or LAN, to play together), where fans may cheer on e-sports athletes. Superdata (2016) reports that $15 \%$ of e-sports viewers are women $(N=430)$, while Gera (2014) suggests that this figure is closer to $30 \%$. However, she also proposes that these women may not self-identify as gamers; they are presumed, instead, to be the family or friends of professional players who take part in the event for their partner's sake. Similarly, N. Taylor, Jenson, and De Castell (2009) note the role of pro-gamers' mothers in organizing their sons' intensive game play activity and travel to gaming events. Two other female roles in e-sports they highlight are 
Preprint of the publication Paaßen et al. (2016). The final publication can be found at DOI:10.1007/s11199-016-0678-y

"booth babes" (female promotional models) and so called "halo hoes," a derogatory term referring to a (probably more imagined than real) group of young women who attend professional gaming events just to flirt with and "pick up" successful male gamers. However, we note a single exception to the dominance of male fandom practices. Cosplay is the practice of dressing up as a character from a video game (Lamerichs, 2011). It is mostly regarded as a female practice (Hjorth, 2009), but is also highly visible, given that cosplay is predominantly featured at gaming conventions and other similar public spaces.

Overall, we see that visible performers of the gamer role are overwhelmingly male. As such, social role theory would predict an association between the male gender and gaming. Thus, social role theory helps to explain the persistence of the male gamer stereotype. We note that this implies a vicious cycle. If gaming is associated with the male gender, women who display their gamer identity face a social cost; for example, women who reveal their gender in multiplayer games are likely to be challenged over their legitimacy and competence (Fox \& Tang, 2014). In turn, fewer women visibly perform their role as a gamer.

Moreover, the lack of visibility of female gamers might impact gendered gaming behavior (e.g., reduced participation of women in domains which are highly visible and professional) by influencing the availability of role models. Role models have been shown to impact motivation, goals, and behavior by making respective domains, goals, and behaviors both more attractive and attainable (Morgenroth, Ryan, \& Peters, 2015). Importantly, research shows that only role models whom individuals believe they could resemble have this positive effect. This is particularly the case for women in male-dominated fields, where other women are more attainable, and in turn more effective, role models (Lockwood, 2006 Stout, Dasgupta, Hunsinger, \& McManus, 2011). The lack of visible female role models in gaming may thus be an additional obstacle which keeps female gamers from visibly performing the role of a gamer.

Additionally, if women are less likely to perform their gamer identity visibly, it is less likely that the video game industry will view them as their target audience. Indeed, the lack of aspirational female characters compared to male characters in current video games may indicate that the target audience is assumed to consist mostly of young men (Behm-Morawitz \& Mastro, 2009; Burgess et al., 2007; Dill \& Thill, 2007; Downs \& Smith, 2010; Martins et al., 2009; Ogletree \& Drake, 2007; Soukup, 2007; Williams, Martins, et al., 2009). Although it can be argued that this lack of female representation in video games does not deter women from playing (Daviault \& Schott, 2013; Reinhard, 2009), it might still limit identification with the gamer label and thus negatively influence women's willingness to perform their gamer identity visibly (Burch \& Wiseman, 2015).

Aside from these subtle structural effects, we also want to highlight the active factors that might limit women's visibility in video game culture. In online games, players are confronted with an overall hostile environment ("trash-talking" or "flaming"; see e.g. Elliott, 2012; Lenhart et al., 2015). This hostile environment is even more pronounced for females. Research shows female gamers are more likely to be targeted for sexual harassment (Barak, 2005; Bucholtz, 2002; 
Preprint of the publication Paaßen et al. (2016). The final publication can be found at DOI:10.1007/s11199-016-0678-y

Cote, 2015). In one experiment, utilizing pre-recorded male and female voices in a violent multiplayer video game, the female voice received three times as many negative comments as the male voice did (Kuznekoff \& Rose, 2013).

Such hostile reactions may be explained by masculine identity and norms. Kilianski (2003) proposes the notion of an "exclusive male identity," which is fundamentally opposed to both femininity and homosexuality. Men whose ideal selves are more masculine, as well as less feminine, are those most likely to hold negative attitudes towards women. This negativity might be particularly strong when women are viewed as threatening a male space by their intrusion. Fox and Tang (2014) suggest that gaming, by virtue of being a space where boys and men typically bond and interact, is viewed as a highly masculine environment. The interplay between this environment and men's own sense of masculine identity can result in these spaces becoming hostile to women. Highly masculine environments can increase adherence to masculine norms, such as those that result in the sexual harassment of women (Mahalik et al., 2003). Women might therefor hide their gender in online gaming spheres to limit hostile reactions, which in turn negatively affects their visibility (Cote, 2015). Finally, we once again note the hostile reaction of a small, but vocal minority in video game culture towards high profile women in gaming (such as video game reviewers or developers), which might deter women from aspiring towards such positions (Consalvo, 2012).

Overall, theories developed in social psychology, combined with the active discrimination women face in (online) gaming spaces, provide a plausible model for the persistence of the male gamer stereotype, despite its arguable lack of accuracy. However, we acknowledge that the empirical support for the applicability of the theories we mentioned in the specific domain of video game culture is still rather thin. Here, further research would be beneficial.

\section{The Consequences of the Male Gamer Stereo- type}

We have discussed the accuracy of the male gamer stereotype and put forward explanations for why the stereotype might be so pervasive. But what are the consequences of this stereotype? As considered in the previous section, the first effect of the male gamer stereotype is its own persistence via feedback loops. The association between gaming and the male gender leads to less visibility of female gamers - due to a reduced feeling of fitting in, reduced self-identification, prescriptive stereotyping, and active discrimination - which in turn leads to a stronger association between gaming and the male gender. We have also seen that the mechanics of the male gamer stereotype lead to a marginalization of women in video game culture. This might lead to negative psychological outcomes such as feeling unwelcome, isolated, or like a misfit in a hobby that is otherwise appealing. Even stronger than that are the direct negative psychological effects of verbal and sexual harassment directed at women, including rape and death threats (Barak, 2005).

As a consequence, women might choose not to play at all or not to play certain 
Preprint of the publication Paaßen et al. (2016). The final publication can be found at DOI:10.1007/s11199-016-0678-y

classes of games. This channeling may preclude them from a range of affective, behavioral, perceptual, cognitive, and physiological benefits (Boyle et al., 2016). Indeed, some research suggests women might benefit more than men do from playing video games. Feng, Spence, and Pratt (2007) found that the gender gap in spatial attention was greatly reduced after playing an action game. Further, video game play is associated with positive social outcomes, such as increased social status for teenagers (Burch \& Wiseman, 2014) as well as making and maintaining friendships via (online) gaming (Lenhart et al., 2015). Finally, several studies have shown that video game play might provide easier access to technological fields of study and work, such as computer science, engineering, and math (STEM fields). Mayo (2009) lists evidence showing that games can close learning gaps between D-grade and B-grade students in science and are associated with higher enjoyment and motivation compared to regular lectures (Mayo, 2009). Daviault (2010) describes an intervention engaging female adolescents in game design, which increased participant's self-efficacy in computer subjects (Daviault, 2010). Finally, Cheryan, Master, and Meltzoff (2015) note that video game play is a part of the computer science stereotype and that women who do not play video games may feel like misfits. Thus, more women engaging in video game play and identifying as gamers might help to alleviate the gender imbalance in some STEM fields (Cheryan et al., 2015; Daviault, 2010).

The male gamer stereotype also informs the perceived audience for game developers (Shaw, 2012, 2013), leading to game content and marketing that panders to a clichéd young male audience, most notably with violent game play and hypersexualized depictions of female characters. The effect of such game content, in turn, is disputed. Whereas some authors suggest that such content might repel women (e.g. Hartmann \& Klimmt, 2006; Vermeulen et al., 2011), others argue that no such effect exists (e.g. Daviault \& Schott, 2013; Reinhard, 2009). It can be argued that violence and hyper-sexualization are problematic for other reasons. For example, Soukup (2007) suggests that most video games are in their very nature masculine and even patriarchal because they promote an idea of mastery that is equivalent to skillfully subjugating and dehumanizing one's opponent. BehmMorawitz and Mastro (2009) found that hyper-sexualized depictions of women affect female players, resulting in lower self-efficacy in women, and they are associated with less favorable attitudes towards women's cognitive and physical abilities in both male and female participants.

Finally, we can also consider the effects of the male gamer stereotype on the research literature itself. Jenson and De Castell (2010) found that a whole branch of scientific literature on gender and gaming has sought to discover innate play preferences of girls and women in order to create games that might appeal to females. This corresponds to the now infamous era of "girl games," which were presumed to be more appropriate for women and girls, but may have instead served to reinforce gendered stereotypes (Harvey \& Fisher, 2015; Jenson \& De Castell, 2010). 


\section{Changes in Video Game Culture}

We have demonstrated that the male gamer stereotype has a whole host of (often negative) effects for women and for gaming in general. This range of issues leads us to our final discussion of whether the male gamer stereotype is likely to disappear in the future and what interventions might help support such a development. Video game culture is not at all static. Games and gamers change rapidly, and video game culture changes in response. Technology has certainly played an important part in these changes, most notably via the omnipresence of smartphones as mobile gaming platforms and the proliferation of broadband internet. Digital game distribution using App Stores or platforms such as Steam has become normal. In his book Casual Revolution, Juul (2009) describes the introduction of casual gaming to mainstream culture - arguably the biggest change to occur in video game culture in recent years. Recent estimates indicate that up to $97 \%$ of American teens play video games, suggesting that almost everyone will be a game-player in the future (Lenhart et al., 2008).

This ubiquity of video game playing has already affected the gamer stereotype, eroding the belief that the typical gamer is unpopular, unattractive, idle, and asocial (Kowert et al., 2014). One could even argue that the identity conflict between gaming as a nerd or geek practice and traditional masculinity has nearly vanished. Burch and Wiseman (2014) suggest that playing popular games is no longer maligned, but rather considered "cool," and can lead to higher social status without any challenge to masculine identity. T. L. Taylor (2012, pp. 128-129) similarly argues that the patriarchal hierarchy might slowly re-incorporate male nerds. However, the situation is less clear for female players.

It is certainly the case that the debate regarding female representation in games has become livelier in recent years. Gaming companies are increasingly engaged with issues of gender representation in games. For instance, Rich Vogel (executive producer of Bethesda, a popular game development company) has stated that the company is taking a conscious approach to creating "aspirational" female characters with appropriate combat outfits and reduced sexualization (Batchelor, 2015). However, female representation is far from being the only issue with regards to gender and gaming (Daviault \& Schott, 2013). Social role theory predicts that more women need to be visible in performing the gamer role in order for the gamer stereotype to change. A more visible representation of women in gaming would likely lead to a higher number of female role models being available to girls and women.

In e-sports, female-only leagues exist, but they have not yet reached an audience similar to the almost exclusively male tournaments (T. L. Taylor, 2012). Although female-only tournaments might lead to greater visibility for women players, it might also reinforce ideas about women and men having different "innate" skill levels, comparable to prevailing notions of different upper-body strength in physical sports where female-only leagues are common. As such, female-only leagues might serve to reinforce, rather than challenge, gendered gamer stereotypes.

It seems, however, that the more important underlying issue is the invisibility 
and marginalization of women in the private sphere of video gaming where female players are still not recognized beyond their roles as mothers, girlfriends, and casual gamers and have to face (or avoid) gender-specific harassment. Recent findings, however, give reason to hope. Burch and Wiseman (2015) found that between 70 and $85 \%$ of U.S.-American male adolescents want to see more female adolescents playing video games $(N \approx 1400)$. Moreover, males already believe that females are playing all different kinds of games. For all genres in question, including those considered hard-core, at least $40 \%$ of about 700 males in their survey agreed that females do play such games. It seems that - similar to the findings of Kowert et al. (2014) regarding other properties of the gamer stereotype -U.S.-American male adolescents do not endorse the male gamer stereotype anymore.

\section{Conclusion}

In the present paper, we investigated the male gamer stereotype in terms of its accuracy, persistence, consequences, and future prospects. Looking at the available body of research on games and gender, we have argued that many women play in the same way their male counterparts do. Thus, the male gamer stereotype is only partially, if at all, accurate. Numerous mechanisms, however, perpetuate the stereotype of gaming as a male activity. Men are more likely to identify as gamers and visibly perform their identity, professionally as well as privately. Conversely, a feminine identity is incongruent with the gamer identity. As a result, female gamers can only be seen as female or as a gamer, reinforcing the belief that being a woman and gaming are fundamentally incompatible. Finally, we have noted that video game culture is actively hostile towards women in the private as well as the professional spheres. Taken together, women are precluded from positive outcomes that are associated with being seen and accepted as true gamers, despite their objectively similar gaming behavior.

In line with social role theory, we predict that this pattern is likely to change if more women are visible in performing their role as gamers. Indeed, first evidence suggests that U.S.-American male adolescents do not endorse the male gamer stereotype anymore. This finding gives reason to hope that the gamer stereotype can be diversified and transformed in order to make video game culture a more welcoming and inclusive space for players across all gender expressions.

\section{Acknowledgments}

Several people provided valuable suggestions and feedback for this paper. Special thanks go to Kristin Bezio, Christine Daviault, Mary Bucholtz and Mia Consalvo.

\section{Compliance with Ethical Standards}

Conflict of Interest The authors declare that they have no conflict of interest. 


\section{A Overview of games mentioned in the present paper}

\begin{tabular}{llllll} 
Title & $\begin{array}{l}\text { Release } \\
\text { date }\end{array}$ & Publisher & $\begin{array}{l}\text { Critic } \\
\text { rating }\end{array}$ & $\begin{array}{l}\text { Player } \\
\text { rating }\end{array}$ & Description \\
\hline Call of Duty & 2003 & Activision & $91 \%$ & $85 \%$ & $\begin{array}{l}\text { The game is set in World War II, where the player assumes the role of a soldier in } \\
\text { the U.S., the British, or the Soviet army, taking part in various historic battles of } \\
\text { the war. Sequels of the game also feature a fictional contemporary warfare setting } \\
\text { (the Modern Warfare titles), secret military operations in different time periods (the } \\
\text { Black Ops titles) and science fiction settings (the Advanced Warfare and Infinite War- } \\
\text { fare installment). Beyond the single-player campaign the games also include extensive } \\
\text { competitive as well as co-operative multiplayer modes. }\end{array}$
\end{tabular}

$\begin{array}{llll}\begin{array}{l}\text { Candy Crush } 2012 \\ \text { Saga }\end{array} & \begin{array}{l}\text { King.com } \\ \text { Limited }\end{array} & 79 \% \quad 28 \% & \begin{array}{l}\text { In each level of the game, the player is presented with a 2D grid of candies. Adjacent } \\ \text { candies can be swapped to form rows of three of the same color, which are then cleared } \\ \text { from the board. }\end{array}\end{array}$

\begin{tabular}{|c|c|}
\hline ter- & 1999 \\
\hline
\end{tabular}

In each match of Counter-Strike, players are distributed into two teams, terrorists and counter-terrorists. These teams are pitted against each other in different game modes. The most common mode is bomb defusal, where the terrorist team tries to plant a bomb and defend it until it explodes, before the counter-terrorist team can defuse it.

Dragon Age: $2009 \quad$ Electronic $\quad 91 \% \quad 86 \%$

Dragon Age: Origins is a single-player game set in a medieval fantasy world, where the player assumes the role of a member of a military order defending the world against demons. Compared to other role playing games, Dragon Age: Origins appears more "adult", covering topics such as racism, religious fanaticism, political intrigue and sexuality, as well as depicting violence rather graphically.

$\begin{array}{ll}\text { Everquest } 2004 \quad \text { Sony } \\ & \text { Online } \\ & \text { Entertain- } \\ & \text { ment }\end{array}$

$83 \% \quad 73 \%$

Players create an avatar which they steer through an extensive medieval fantasy world, working on tasks provided by non-player characters. Finishing such tasks or killing opponent is rewarded with in-game money as well as experience points, which enable players to level up their avatar until a maximum level is reached. Challenges remaining at maximum level include combat against other player-controlled avatars (player versus player or $\mathrm{PvP}$ ) or large scale group efforts (with up to 24 players) to progress through a dungeon guarded by particularly strong non-playable characters. 


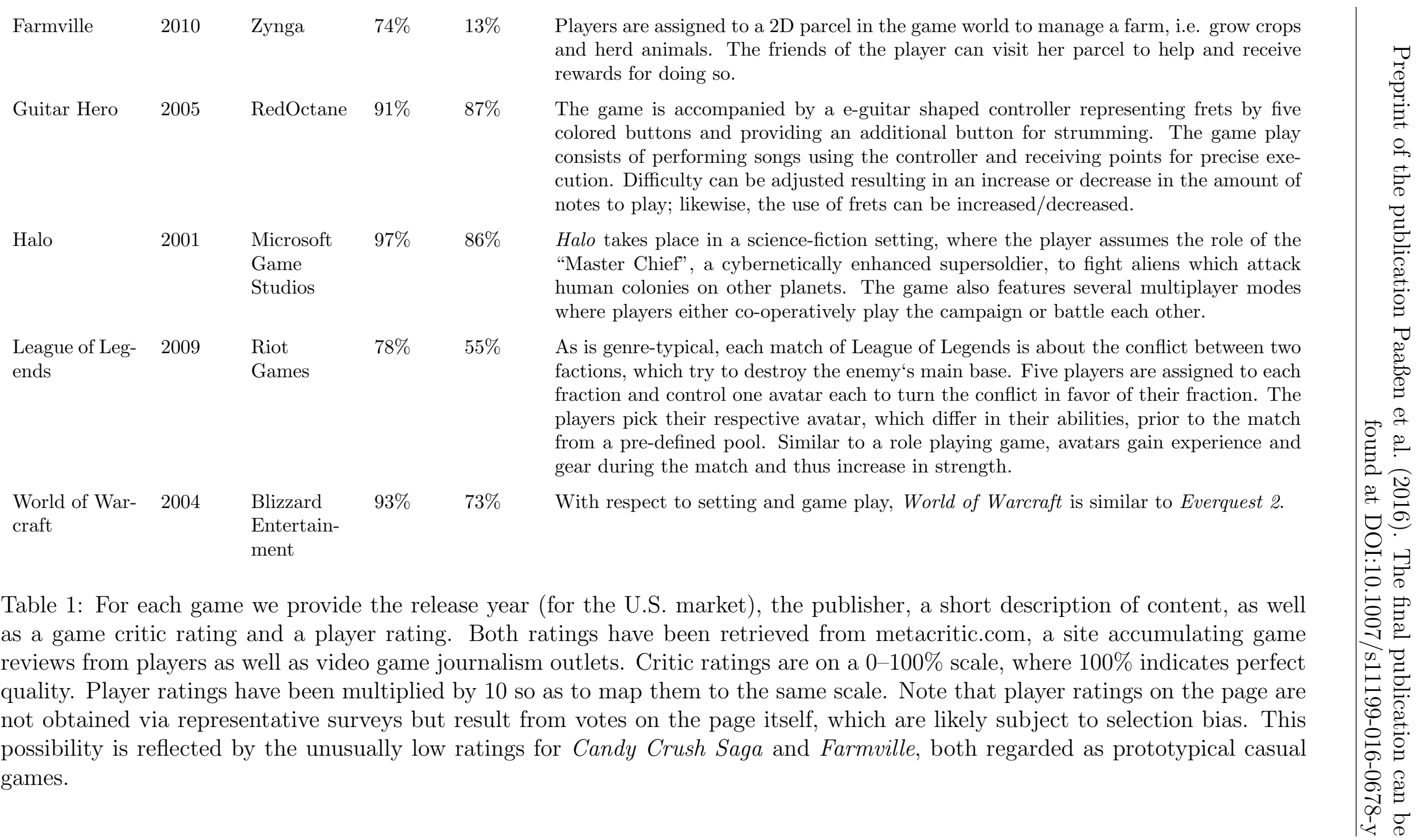


Preprint of the publication Paaßen, Morgenroth, \& Stratemeyer (2016). The final publication can be found at DOI:10.1007/s11199-016-0678-y

\section{References}

alexa.com. (2016). Top sites in video games. Retrieved January 2, 2016, from http://www.alexa.com/topsites/category;0/Top/Games/Video_Games

Alexander, L. (2014, September 5). Sexism, lies and video games: The culture war nobody is winning. Retrieved January 2, 2016, from http://time.com/ $3274247 /$ video-game-culture-war/

Barak, A. (2005). Sexual harassment on the internet. Social Science Computer Review, 23(1), 77-92. doi:10.1177/0894439304271540

Batchelor, J. (2015, June 18). Executive producer rich vogel says studio was keen to make sure its female cast didn't look like strippers. Retrieved from http: //www.develop-online.net/news/e3-2015-bethesda-aiming-for-aspirationalfemale-characters-in-battlecry/0208013

Behm-Morawitz, E. \& Mastro, D. (2009). The effects of the sexualization of female video game characters on gender stereotyping and female self-concept. Sex Roles, 61 (11-12), 808-823. doi:10.1007/s11199-009-9683-8

Boyle, E. A., Hainey, T., Connolly, T. M., Gray, G., Earp, J., Ott, M., ... Pereira, J. (2016). An update to the systematic literature review of empirical evidence of the impacts and outcomes of computer games and serious games. Computers \& Education, 94, 178-192. doi:10.1016/j.compedu.2015.11.003

Brown, R. M., Hall, L. R., Holtzer, R., Brown, S. L., \& Brown, N. L. (1997). Gender and video game performance. Sex Roles, 36(11), 793-812. doi:10.1023/A: 1025631307585

Bucholtz, M. (2002). Geek feminism. In S. Benor, M. Rose, D. Sharma, J. Sweetland, \& Q. Zhang (Eds.), Gendered Practices in Language (pp. 277-307). Stanford, CA: CSLI.

Burch, A. \& Wiseman, R. (2015, March 4). Curiosity, courage and camouflage: Revealing the gaming habits of teen girls. In Game Developers Conference. Retrieved January 2, 2016, from http://www.gdcvault.com/play/1021899/ Curiosity-Courage-and-Camouflage-Revealing

Burch, A. \& Wiseman, R. (2014, March 18). The connection between boys' social status, gaming and conflict. In Game Developers Conference. Retrieved January 2, 2016, from http://www.gdcvault.com / play / 1020370/TheConnection-Between-Boys-Social

Burgess, M. C., Stermer, S. P., \& Burgess, S. R. (2007). Sex, lies, and video games: The portrayal of male and female characters on video game covers. Sex Roles, 57(5-6), 419-433. doi:10.1007/s11199-007-9250-0

Cheryan, S., Master, A., \& Meltzoff, A. N. (2015). Cultural stereotypes as gatekeepers: Increasing girls' interest in computer science and engineering by diversifying stereotypes. Frontiers in Psychology, 6(49). doi:10.3389/fpsyg. 2015.00049

Chess, S. \& Shaw, A. (2015). A conspiracy of fishes, or, how we learned to stop worrying about \#GamerGate and embrace hegemonic masculinity. Journal of Broadcasting $\&$ Electronic Media, 59(1), 208-220. doi:10.1080/08838151. 2014.999917 
Preprint of the publication Paaßen, Morgenroth, \& Stratemeyer (2016). The final publication can be found at DOI:10.1007/s11199-016-0678-y

Consalvo, M. (2012). Confronting toxic gamer culture: A challenge for feminist game studies scholars. Ada: A Journal of Gender, New Media, and Technology, (1). doi:10.7264/N33X84KH

Cote, A. C. (2015). "I can defend myself" Women's strategies for coping with harassment while gaming online. Games and Culture. doi:10.1177/1555412015587603

Daviault, C. (2010). Finding the right fit: The women in IT dilemma. In L. Gomez Choca, D. Marti Belenguer, \& I. Candel Torres (Eds.), Proceedings of the 3rd International Conference of Education, Research and Innovation (pp. 59966004). Madrid, Spain: International Association of Technology, Education and Development.

Daviault, C. \& Schott, G. (2013). Looking beyond representation - Situating the significance of gender portrayal within game play. In C. C. Carter, L. Steiner, \& L. McLaughlin (Eds.), The Routledge Companion to Media and Gender (pp. 440-449). Didcot, UK: Milton Park.

Dill, K. E. \& Thill, K. P. (2007). Video game characters and the socialization of gender roles: Young people's perceptions mirrorsexist media depictions. Sex Roles, 57(11-12), 851-864. doi:10.1007/s11199-007-9278-1

Downs, E. \& Smith, S. L. (2010). Keeping abreast of hypersexuality: A video game character content analysis. Sex Roles, 62 (11-12), 721-733. doi:10.1007/ s11199-009-9637-1

Eagly, A. H. \& Steffen, V. J. (1984). Gender stereotypes stem from the distribution of women and men into social roles. Journal of Personality and Social Psychology, 46 (4), 735. doi:10.1037/0022-3514.46.4.735

Elliott, T. P. (2012). Flaming and gaming-computer-mediated-communication and toxic disinhibition. University of Twente.

Entertainment Software Association. (2008). Essential facts about the computer and video game industry. Retrieved January 2, 2016, from https://library. princeton.edu/sites/default/files/2008.pdf

Entertainment Software Association. (2009). Essential facts about the computer and video game industry. Retrieved January 2, 2016, from https://library. princeton.edu/sites/default/files/2009.pdf

Entertainment Software Association. (2010). Essential facts about the computer and video game industry. Retrieved January 2, 2016, from http://www.isfe. eu/sites/isfe.eu/files/attachments/esa_ef_2010.pdf

Entertainment Software Association. (2011). Essential facts about the computer and video game industry. Retrieved January 2, 2016, from http://www.isfe. eu/sites/isfe.eu/files/attachments/esa_ef_2011.pdf

Entertainment Software Association. (2012). Essential facts about the computer and video game industry. Retrieved January 2, 2016, from http://www.isfe. eu/sites/isfe.eu/files/attachments/esa_ef_2012.pdf

Entertainment Software Association. (2013). Essential facts about the computer and video game industry. Retrieved January 2, 2016, from http://www.isfe. eu/sites/isfe.eu/files/attachments/esa_ef_2013.pdf 
Preprint of the publication Paaßen, Morgenroth, \& Stratemeyer (2016). The final publication can be found at DOI:10.1007/s11199-016-0678-y

Entertainment Software Association. (2014). Essential facts about the computer and video game industry. Retrieved January 2, 2016, from http://www.isfe. eu/sites/isfe.eu/files/attachments/esa_ef_2014.pdf

Entertainment Software Association. (2015). Essential facts about the computer and video game industry. Retrieved October 5, 2015, from http://www. theesa.com/wp-content/uploads/2015/04/ESA-Essential-Facts-2015.pdf

esportsearnings.com. (2016). Highest overall earnings. Retrieved January 2, 2016, from http://www.esportsearnings.com/players

Feng, J., Spence, I., \& Pratt, J. (2007). Playing an action video game reduces gender differences in spatial cognition. Psychological Science, 18(10), 850855. doi:10.1111/j.1467-9280.2007.01990.x

Fine, C. (2010). Delusions of gender: How our minds, society, and neurosexism create difference. New York, NY: WW Norton \& Company.

Fiske, S. T., Cuddy, A. J. C., Glick, P., \& Xu, J. (2002). A model of (often mixed) stereotype content: Competence and warmth respectively follow from perceived status and competition. Journal of Personality and Social Psychology, 82 (6), 878-902. doi:10.1037/0022-3514.82.6.878

Fox, J. \& Tang, W. Y. (2014, April). Sexism in online video games: The role of conformity to masculine norms and social dominance orientation. Comput. Hum. Behav. 33, 314-320. doi:10.1016/j.chb.2013.07.014

Gera, E. (2014, May 27). Where are the women in eSports? Retrieved January 2, 2016, from http://www.polygon.com/2014/5/27/5723446/women-inesports-professional-gaming-riot-games-blizzard-starcraft-lol

Grooten, J. \& Kowert, R. (2015). Going beyond the game: Development of gamer identities within societal discourse and virtual spaces. Loading ... 9(14), 7087. Retrieved from http://journals.sfu.ca/loading/index.php/loading/ article/viewArticle/151

Grüsser, S. M., Thalemann, R., \& Griffiths, M. D. (2006). Excessive computer game playing: Evidence for addiction and aggression? Cyberpsychology, Behavior, and Social Networking, 10(2), 290-292. doi:10.1089/cpb.2006.9956

Haagsma, M. C., Pieterse, M. E., \& Peters, O. (2012). The prevalence of problematic video gamers in the netherlands. Cyberpsychology, Behavior, and Social Networking, 15(3), 162-168. doi:10.1089/cyber.2011.0248

Haferkamp, N. \& Herbers, M. R. (2012). What if Bourdieu had played FarmVille? examining users' motives for playing the browser game FarmVille in relation to socio-demographic variables. Publizistik, 57(2), 205-223. doi:10.1007/ s11616-012-0144-y

Hartmann, T. \& Klimmt, C. (2006). Gender and computer games: Exploring females' dislikes. Journal of Computer-Mediated Communication, 11 (4), 910931. doi:10.1111/j.1083-6101.2006.00301.x

Harvey, A. \& Fisher, S. (2015). "Everyone can make games!": The post-feminist context of women in digital game production. Feminist Media Studies, 15(4), 576-592. doi:10.1080/14680777.2014.958867

Harwell, D. (2014, October 17). More women play video games than boys, and other surprising facts lost in the mess of Gamergate. The Switch (Blog). 
Preprint of the publication Paaßen, Morgenroth, \& Stratemeyer (2016). The final publication can be found at DOI:10.1007/s11199-016-0678-y

Retrieved January 2, 2016, from http://www.washingtonpost.com/blogs/ the-switch/wp/2014/10/17/more-women-play-video-games-than-boys-andother-surprising-facts-lost-in-the-mess-of-gamergate/

Hjorth, L. (2009). Game girl: Reimagining japanese gender and gaming via Melbourne female cosplayers. Intersections: Gender and Sexuality in Asia and the Pacific, 20(1), 1-11.

Huntemann, N. B. (2013). Introduction: Feminist discourses in games/game studies. Ada: A Journal of Gender, New Media, and Technology, (2). doi:10.7264/ N37D2S2F

Huntemann, N. B. (2012). Women in video games: The case of hardware production and promotion. In Gaming Globally: Production, Play, and Place (p. 41). London, UK: Palgrave Macmillan.

Interactive Software Federation of Europe. (2012). Videogames in europe: consumer study. Retrieved January 2, 2016, from http://www.isfe.eu/videogameseurope-2012-consumer-study

Ip, B. \& Jacobs, G. (2005). Segmentation of the games market using multivariate analysis. Journal of Targeting, Measurement and Analysis for Marketing, 13(3), 275-287. doi:10.1057/palgrave.jt.5740154

Jenson, J. \& De Castell, S. (2010). Gender, simulation, and gaming: Research review and redirections. Simulation \& Gaming, 41(1), 51-71. doi:10.1177/ 1046878109353473

Jussim, L., Cain, T. R., Crawford, J. T., Harber, K., \& Cohen, F. (2009). The unbearable accuracy of stereotypes. In T. Nelson (Ed.), Handbook of prejudice, stereotyping, and discrimination (pp. 199-227). Hillsdale, NJ: Erlbaum.

Jussim, L., Crawford, J. T., \& Rubinstein, R. S. (2015). Stereotype (in)accuracy in perceptions of groups and individuals. Current Directions in Psychological Science, 24 (6), 490-497. doi:10.1177/0963721415605257

Juul, J. (2009). A casual revolution: Reinventing video games and their players. Cambridge, MA: MIT Press.

Kahn, A. S., Ratan, R., \& Williams, D. (2014). Why we distort in self-report: Predictors of self-report errors in video game play. Journal of ComputerMediated Communication, 19(4), 1010-1023. doi:10.1111/jcc4.12056

Kaye, L. K. \& Pennington, C. R. (2016). "girls can't play": The effects of stereotype threat on females' gaming performance. Computers in Human Behavior, 59, 202-209. doi:10.1016/j.chb.2016.02.020

Kilianski, S. E. (2003). Explaining heterosexual men's attitudes toward women and gay men: The theory of exclusively masculine identity. Psychology of Men \& Masculinity, 4(1), 37-56. doi:10.1037/1524-9220.4.1.37

Koenig, A. M. \& Eagly, A. H. (2014). Evidence for the social role theory of stereotype content: Observations of groups' roles shape stereotypes. Journal of Personality and Social Psychology, 107(3), 371. doi:10.1037/a0037215

Kowert, R., Festl, R., \& Quandth, T. (2014). Unpopular, overweight, and socially inept: Reconsidering the stereotype of online gamers. Cyberpsychology, Behavior and Social Networking, 17(3), 141-146. doi:10.1089/cyber.2013.0118 
Preprint of the publication Paaßen, Morgenroth, \& Stratemeyer (2016). The final publication can be found at DOI:10.1007/s11199-016-0678-y

Kowert, R., Griffiths, M. D., \& Oldmeadow, J. A. (2012). Geek or chic? Emerging stereotypes of online gamers. Bulletin of Science, Technology 85 Society, 32(6), 471-479. doi:10.1177/0270467612469078

Kuznekoff, J. H. \& Rose, L. M. (2013). Communication in multiplayer gaming: Examining player responses to gender cues. New Media 6 Society, 15(4), 541-556. doi:10.1177/1461444812458271

Lamerichs, N. (2011). Stranger than fiction: Fan identity in cosplay. Transformative Works and Cultures, \%. doi:10.3983/twc.2011.0246

Latrofa, M., Vaes, J., Cadinu, M., \& Carnaghi, A. (2010). The cognitive representation of self-stereotyping. Personality and Social Psychology Bulletin, 36(7), 911-922. doi:10.1177/0146167210373907

Lenhart, A., Kahne, J., Middaugh, E., Macgill, A. R., Evans, C., \& Vitak, J. (2008, September 16). Teens, video games, and civics: Teens' gaming experiences are diverse and include significant social interaction and civic engagement. Pew Internet \& American Life Project. Retrieved from http:// www.pewinternet.org/2008/09/16/teens-video-games-and-civics/

Lenhart, A., Smith, A., Anderson, M., Duggan, M., \& Perrin, A. (2015, August 6). Teens, technology and friendships. Pew Research Center. Retrieved from http: / / www . pewinternet.org / 2015/08/06/teens- technology-andfriendships/

Lockwood, P. (2006). "Someone like me can be successful": Do college students need same-gender role models? Psychology of Women Quarterly, 30(1), 3646. doi:10.1111/j.1471-6402.2006.00260.x

Maddox. (2013, June 6). Quick rant - the solution to sexism in video games! Retrieved January 3, 2016, from https://www.youtube.com/watch?v= MpJGkG1g-Lk

Mahalik, J. R., Locke, B. D., Ludlow, L. H., Diemer, M. A., Scott, R. P. J., Gottfried, M., \& Freitas, G. (2003). Development of the conformity to masculine norms inventory. Psychology of Men ES Masculinity, 4(1), 3-25. doi:10.1037/ 1524-9220.4.1.3

Martins, N., Williams, D. C., Harrison, K., \& Ratan, R. A. (2009). A content analysis of female body imagery in video games. Sex Roles, 61(11-12), 824836. doi:10.1007/s11199-009-9682-9

Mayo, M. J. (2009). Video games: A route to large-scale STEM education? Science, 323(5910), 79-82. doi:10.1126/science.1166900

Mentzoni, R. A., Brunborg, G. S., Molde, H., Myrseth, H., Skouverøe, K. J. M., Hetland, J., \& Pallesen, S. (2011). Problematic video game use: Estimated prevalence and associations with mental and physical health. Cyberpsychology, Behavior, and Social Networking, 14(10), 591-596. doi:10.1089/cyber. 2010.0260

Morgenroth, T., Ryan, M. K., \& Peters, K. (2015). The motivational theory of role modeling: How role models influence role aspirants' goals. Review of General Psychology, 19(4), 465. doi:10.1037/gpr0000059 
Preprint of the publication Paaßen, Morgenroth, \& Stratemeyer (2016). The final publication can be found at DOI:10.1007/s11199-016-0678-y

Nguyen, H.-H. D. \& Ryan, A. M. (2008, November). Does stereotype threat affect test performance of minorities and women? A meta-analysis of experimental evidence. Journal of Applied Psychology, 93(6), 1314-1334.

Ogletree, S. M. \& Drake, R. (2007). College students' video game participation and perceptions: Gender differences and implications. Sex Roles, 56(7-8), $537-542$.

Paaßen, B., Morgenroth, T., \& Stratemeyer, M. (2016). What is a true gamer? The male gamer stereotype and the marginalization of women in video game culture. Sex Roles. in press. doi:10.1007/s11199-016-0678-y

Parker, F. (2008). The significance of jeep tag: On player-imposed rules in video games. Loading... 2(3). Retrieved from http://journals.sfu.ca/loading/index. $\mathrm{php} /$ loading/article/viewarticle/44

PEGI. (2016). Dragon Age. Retrieved January 3, 2016, from http://www.pegi. info/en/index/global_id/505/?searchString=dragon+age

Poels, Y., Annema, J. H., Verstraete, M., Zaman, B., \& De Grooff, D. (2012). Are you a gamer? A qualititive study on the parameters for categorizing casual and hardcore gamers. Iadis International Journal on www/internet, 10(1), $1-16$.

Prescott, J. \& Bogg, J. (2013). The gendered identity of women in the games industry. Eludamos. Journal for Computer Game Culture, 7(1), 55-67.

Ratan, R. A., Taylor, N., Hogan, J., Kennedy, T., \& Williams, D. (2015). Stand by your man: An examination of gender disparity in league of legends. Games and Culture, 10(5), 438-462. doi:10.1177/1555412014567228

Reinhard, C. D. (2009). Hypersexualism in video games as determinant or deterrent of game play: Do men want them and do women want to be them? Roskilde Universitet.

Ridgeway, C. L. (2013). Why status matters for inequality. American Sociological Review, 79(1), 1-16. doi:10.1177/0003122413515997

Royse, P., Lee, J., Undrahbuyan, B., Hopson, M., \& Consalvo, M. (2007). Women and games: technologies of the gendered self. New Media \&5 Society, 9(4), 555-576. doi:10.1177/1461444807080322

Salter, A. \& Blodgett, B. (2012). Hypermasculinity \& dickwolves: The contentious role of women in the new gaming public. Journal of Broadcasting \& Electronic Media, 56 (3), 401-416. doi:10.1080/08838151.2012.705199

Sarkeesian, A. (2013). Tropes versus women in video games. Retrieved January 3, 2016, from https://www.youtube.com/playlist? list=PLn4ob_5_ttEaA_ vc8F3fjzE62esf9yP61

Shaw, A. (2012). Do you identify as a gamer? Gender, race, sexuality, and gamer identity. New Media \&5 Society, 14 (1), 28-44. doi:10.1177/1461444811410394

Shaw, A. (2013). On not becoming gamers: Moving beyond the constructed audience. Ada: A Journal of Gender, New Media, and Technology, (2). doi doi: 10.7264/N33N21B3

Shaw, A. (2010). What is video game culture? Cultural studies and game studies. Games and Culture, 5(4), 403-424. doi:10.1177/1555412009360414 
Preprint of the publication Paaßen, Morgenroth, \& Stratemeyer (2016). The final publication can be found at DOI:10.1007/s11199-016-0678-y

Shaw, A. \& Chess, S. (2016). Reflections on the casual games market in a postGamerGate world. In M. Willson \& T. Leaver (Eds.), Social, Casual and Mobile Games: The Changing Gaming Landscape (p. 277). New York, NY: Bloomsbury Publishing USA.

Soukup, C. (2007). Mastering the game: Gender and the entelechial motivational system of video games. Women's Studies in Communication, 30(2), 157-178. doi:10.1080/07491409.2007.10162511

Spears, R., Doosje, B., \& Ellemers, N. (1997). Self-stereotyping in the face of threats to group status and distinctiveness: The role of group identification. Personality and Social Psychology Bulletin, 23(5), 538-553. doi:10.1177/ 0146167297235009

Stark, C. (2015, July 22). PewDiePie's youtube success put him on the cover of 'Variety.' Mashable. Retrieved from http://mashable.com/2015/07/22/ pewdiepie-variety/\#eZv2zr0FFOq0

Steele, C. M. \& Aronson, J. (1995). Stereotype threat and the intellectual test performance of African Americans. Journal of Personality and Social Psychology, 69(5), 797-811.

Storla, K. D. (2011). Boyfriends, babies, and a few good headshots: Examining girl gamers' identity enactment on Twitter using the communication theory of identity (Bachelor of Arts, Georgia State University).

Stout, J. G., Dasgupta, N., Hunsinger, M., \& McManus, M. A. (2011). STEMing the tide: using ingroup experts to inoculate women's self-concept in science, technology, engineering, and mathematics (STEM). Journal of Personality and Social Psychology, 100(2), 255-270. doi:10.1037/a0021385

Summers, C. H. (2014, September 16). Are video games sexist? Retrieved January 3, 2016, from https://www.youtube.com/watch?v=9MxqSwzFy5w

Superdata. (2016). eSports: The 2016 report (preview). SuperData Research. Retrieved from https://superdata-research.myshopify.com/products/spring2016-esports-market-report?variant $=24025595907$

Tajfel, H. (1974). Social identity and intergroup behaviour. Social Science Information, 13(2), 65-93. doi:10.1177/053901847401300204

Taylor, N., Jenson, J., \& De Castell, S. (2009). Cheerleaders/booth babes/halo hoes: Pro-gaming, gender and jobs for the boys. Digital Creativity, 20(4), 239-252. doi:10.1080/14626260903290323

Taylor, T. L. (2012). Raising the stakes: E-sports and the professionalization of computer gaming. Cambridge, MA: MIT Press.

Terlecki, M., Brown, J., Harner-Steciw, L., Irvin-Hannum, J., Marchetto-Ryan, N., Ruhl, L., \& Wiggins, J. (2011). Sex differences and similarities in video game experience, preferences, and self-efficacy: Implications for the gaming industry. Current Psychology, 30(1), 22-33. doi:10.1007/s12144-010-9095-5

The Amazing Atheist. (2013, June 3). Refuting Anita Sarkeesian's "damsel in distress: part 2". Retrieved January 3, 2016, from https://www.youtube. $\mathrm{com} /$ watch? $\mathrm{v}=25 \mathrm{o} 0 \mathrm{EZiogw} 0 \# \mathrm{t}=4 \mathrm{~m} 30 \mathrm{~s}$ 
Preprint of the publication Paaßen et al. (2016). The final publication can be found at DOI:10.1007/s11199-016-0678-y

thunderf00t. (2014, July 4). 'Feminism' vs facts (Anita Sarkeesian destroyed!) Retrieved January 3, 2016, from https://www.youtube.com/watch?v=19Ju1I1DTU\#t=22m04s

Turner, J. C., Oakes, P. J., Haslam, S. A., \& McGarty, C. (1994). Self and collective: Cognition and social context. Personality and Social Psychology Bulletin, 20 (5), 454-463. doi:10.1177/0146167294205002

Vanderhoef, J. (2013). Casual threats: The feminization of casual video games. Ada: A Journal of Gender, New Media, and Technology, (2). doi:10.7264/ N3V40S4D

Vaughan, L. \& Yang, R. (2013). Web traffic and organization performance measures: Relationships and data sources examined. Journal of Informetrics, 7(3), 699-711. doi:10.1016/j.joi.2013.04.005

Vermeulen, L., Castellar, E. N., Janssen, D., Calvi, L., \& Looy, J. V. (2016). Playing under threat. Examining stereotype threat in female game players. Computers in Human Behavior, 57, 377-387. doi:10.1016/j.chb.2015.12.042

Vermeulen, L., Van Looy, J., De Grove, F., \& Courtois, C. (2011). You are what you play?: A quantitative study into game design preferences across gender and their interaction with gaming habits. In Proceedings of the $2011 \mathrm{Di}$ GRA International Conference: Think Design Play. Digital Games Research Association (DiGRA). Utrecht, Netherlands.

vidstatx.com. (2015). One hundred most subscribed games \& gaming channel rankings list by subscribers. Retrieved November 28, 2015, from http://vidstatsx. com/youtube-top-100-most-subscribed-games-gaming-channels

Williams, D. (2005). A brief social history of video games. In Proceedings of the 2005 DiGRA International Conference: Changing views - Worlds in play. Vancouver, Canada: Digital Games Research Association (DiGRA). Retrieved from http://www.digra.org/wp-content/uploads/digital-library/ 06278.32314.pdf

Williams, D. (2003). The video game lightning rod. Information, Communication E3 Society, 6(4), 523-550. doi:10.1080/1369118032000163240

Williams, D., Consalvo, M., Caplan, S., \& Yee, N. (2009). Looking for gender: Gender roles and behaviors among online gamers. Journal of Communication, 59(4), 700-725. doi:10.1111/j.1460-2466.2009.01453.x

Williams, D., Martins, N., Consalvo, M., \& Ivory, J. D. (2009). The virtual census: Representations of gender, race and age in video games. New Media $\mathcal{6}$ Society, 11 (5), 815-834. doi:10.1177/1461444809105354

Williams, D., Yee, N., \& Caplan, S. E. (2008). Who plays, how much, and why? Debunking the stereotypical gamer profile. Journal of Computer-Mediated Communication, 13(4), 993-1018. doi:10.1111/j.1083-6101.2008.00428.x

Wingfield, N. (2014, October 15). Feminist critics of video games facing threats in 'GamerGate' campaign. Retrieved July 21, 2016, from http://www.nytimes. com/2014/10/16/technology/gamergate-women-video-game-threats-anitasarkeesian.html

Winn, J. \& Heeter, C. (2009). Gaming, gender, and time: Who makes time to play? Sex Roles, 61 (1-2), 1-13. doi:10.1007/s11199-009-9595-7 